\title{
Patient's and physician's awareness of kidney disease in coronary heart disease patients - a cross-sectional analysis of the German subset of the EUROASPIRE IV survey
}

Martin Wagner ${ }^{1,2,3^{*}}$, Christoph Wanner ${ }^{2}$, Martin Schich ${ }^{1,3}$, Kornelia Kotseva ${ }^{4,5,10}$, David Wood ${ }^{4}$, Katrin Hartmann ${ }^{1,2}$, Georg Fette ${ }^{3,6}$, Viktoria Rücker ${ }^{1}$, Mehmet Oezkur ${ }^{3,7}$, Stefan Störk ${ }^{3,8}$ and Peter U. Heuschmann ${ }^{1,3,9}$

\begin{abstract}
Background: Chronic kidney disease (CKD) is a common comorbid condition in coronary heart disease (CHD). CKD predisposes the patient to acute kidney injury (AKI) during hospitalization. Data on awareness of kidney dysfunction among CHD patients and their treating physicians are lacking. In the current cross-sectional analysis of the German EUROASPIRE IV sample we aimed to investigate the physician's awareness of kidney disease of patients hospitalized for CHD and also the patient's awareness of CKD in a study visit following hospital discharge.

Methods: All serum creatinine ( $\mathrm{SCr}$ ) values measured during the hospital stay were used to describe impaired kidney function (eGFR KKD-EPI $_{2} 60 \mathrm{ml} / \mathrm{min} / 1.73 \mathrm{~m}^{2}$ ) at admission, discharge and episodes of AKI (KDIGO definition). Information extracted from hospital discharge letters and correct ICD coding for kidney disease was studied as a surrogate of physician's awareness of kidney disease. All patients were interrogated 0.5 to 3 years after hospital discharge, whether they had ever been told about kidney disease by a physician.

Results: Of the 536 patients, 32\% had evidence for acute or chronic kidney disease during the index hospital stay. Either condition was mentioned in the discharge letter in $22 \%$, and $72 \%$ were correctly coded according to ICD-10. At the study visit in the outpatient setting 35\% had impaired kidney function. Of 158 patients with kidney disease, 54 (34\%) were aware of CKD. Determinants of patient's awareness were severity of CKD (OR eGFR $0.94 ; 95 \% \mathrm{Cl} 0.92-0.96$ ), obesity (OR 1.97; 1.07-3.64), history of heart failure (OR 1.99; 1.00-3.97), and mentioning of kidney disease in the index event's hospital discharge letter (OR 5.51; 2.35-12.9).
\end{abstract}

Conclusions: Although CKD is frequent in CHD, only one third of patients is aware of this condition. Patient's awareness was associated with kidney disease being mentioned in the hospital discharge letter. Future studies should examine how raising physician's awareness for kidney dysfunction may improve patient's awareness of CKD.

Keywords: Coronary heart disease, Chronic kidney disease, Patients' awareness, Physicians' awareness, ICD-coding of CKD, EUROASPIRE survey

\footnotetext{
* Correspondence: wagner_m@ukw.de

'Institute of Clinical Epidemiology and Biometry, University of Würzburg,

Petrinistr. 33a, 97080 Würzburg, Germany

2Division of Nephrology, Department of Medicine I, University Hospital

Würzburg, Würzburg, Germany

Full list of author information is available at the end of the article
} 


\section{Background}

Chronic kidney disease (CKD) has been identified as a common and important risk factor in patients with coronary heart disease (CHD) [1-4]. Patients with CKD represent a multi-morbid population [5] which is at risk for various complications, e.g. episodes of acute kidney injury (AKI), in hospital stays of various causes, including CHD [6]. CKD and AKI impact independently on morbidity and mortality, even if classic cardiovascular risk factors, such as hypertension, diabetes, and dyslipidemia are controlled [7-10]. The health economic relevance of kidney disease, acknowledging multi-morbidity of patients and risk for complications, is also reflected by the fact that adequate ICD-10 coding for CKD and AKI impacts on reimbursement [11].

Early referral to nephrology or specialist care for impaired kidney function is associated with a reduced risk of CHD events, CKD progression, and mortality [12]. To decide on treatment goals and educate the patient, nephrology care suggests determining the risk of an individual patient for disease progression [13]. The awareness of CKD in the general population and in CKD cohorts is limited $[14,15]$. It is suggested that well-informed patients aware of their disease may show better adherence to medication and may easier achieve treatment targets [16, 17].

In CHD, many patients and physicians know about of the importance of classic cardiovascular (CV) risk factors, treatment targets, and lifestyle advice such as smoking cessation, diet, or physical activity [18, 19]. However, implementation of guideline recommendations into daily practice is still far from optimal [20]. Evidence is sparse regarding the perception of kidney disease in patients with CHD [21], both from the perspective of patients as of physicians. Herein, to report on important inhospital events including e.g. chronic and/or acute deterioration of kidney function in discharge letters is important to transfer information from the hospital to the ambulatory setting.

In the current study, we analyzed (a) how chronic and/ or acutely impaired kidney function is reported in the discharge letter after hospitalization for CHD and (b) the completeness of ICD coding for CKD and AKI as reflection the physician's awareness of kidney disease. We also describe the level of CKD awareness in CHD patients in the ambulatory setting following hospital discharge.

\section{Methods}

\section{Patient population and study setting}

We used data of the German sample $(n=536)$ of the EUROASPIRE IV survey [20]. The EUROpean Action on Secondary and Primary Prevention by Intervention to Reduce Events surveys are a multinational initiative of the European Society of Cardiology and the European Association for Cardiovascular Prevention and Rehabilitation to assess quality of secondary prevention in CHD patients across Europe [19]. The study design of the EUROASPIRE IV "hospital-arm" has been reported previously [20]. Briefly, for each participating country, a geographical region with $>0.5$ million people was selected in which at least one hospital offering interventional cardiology and cardiac surgery and one or more acute hospitals admitting patients with MI and myocardial ischemia. All patients hospitalized for acute or elective treatment of CHD (coronary artery bypass grafting [CABG], percutaneous coronary intervention [PCI], acute myocardial infarction, or myocardial ischemia) were identified from the hospital's patient management systems and invited to participate in the study. This "index" CHD-event could represent the primary diagnosis of $\mathrm{CHD}$ as well as any subsequent episode in previously established CHD. Subjects were eligible if they were 18-79 years old and the study visit took place between 6 and 36 months after the index hospital stay. All participants provided written informed consent. At the German study center, patients were recruited from the University Hospital Wuerzburg (Dept. of Medicine I and Department for Thoracic and Cardiovascular Surgery) and the Klinik Kitzinger Land (Dept. of Medicine). The study protocol and data-handling at the German study center were approved by the Ethics Committee of the Medical Faculty of the University of Würzburg (Vote 58/12) and the data protection officers of the University Hospital and the University of Würzburg (DS-117.605-15/12).

\section{Data collection}

Information on the $\mathrm{CHD}$ event, risk factors, clinical measurements and laboratory values (e.g. SCr at hospital admission) were obtained by retrospective review of index hospitalization charts. During the study visit, details of CHD history (e.g. MI, CABG, PCI/stent) and information on co-morbid conditions, medication, lifestyle and behavior were collected in personal interviews, and standardized examinations were performed according to the EUROASPIRE IV protocol, including blood pressure, weight, height, carbon monoxide (CO) in exhaled air [22]. Serum creatinine (SCr), lipid profile and HbA1c were analyzed centrally from fasting blood samples at the National Public Health Institute, Helsinki, Finland. In addition, urinary albumin/creatinine ratio (ACR) was measured locally.

In addition to the core EUROASPIRE IV protocol, we implemented a kidney module at the German study center a few weeks after the start of enrollment, thus respective information was missing in $n=62$ (11.6\%) individuals. Additional information relating to kidney function during the index hospitalization, i.e. details of CKD or AKI, including dialysis requirement, reported in the discharge letter, was collected by chart review. For all German patients we were able to retrospectively 
collect laboratory data on $\mathrm{SCr}$ at hospital discharge and the maximum value of $\mathrm{SCr}$ during the hospital stay. For patients admitted to the University Hospital Würzburg $(n=498)$ the Data Warehouse of the Comprehensive Heart Failure Center [23] was utilized, e.g. for extraction of $\mathrm{SCr}$ values, ICD-10 codes for CKD and AKI, and OPS-codes for dialysis treatment. At the study visit, we collected data on the patient's awareness of CKD and specialist care during personal interviews. It included the following questions: "Have you ever been told by a doctor/health care provider that your kidney function is impaired, e.g. not as good as it would be expected?"; "Have you ever been told by a doctor/health care provider that you should be seen by a specialist to have your kidney function checked?"; "Have you ever been seen by a specialist to have your kidney function checked and/or treated?".

\section{Presence of CKD}

Kidney function was categorized into CKD-G and CKD-A stages based on estimated glomerular filtration rate $\left(\mathrm{eGFR}_{\mathrm{CKD} \text {-EPI }}\right.$ ) and ACR according to KDIGO (Kidney Disease: Improving Global Outcomes) [24] (Fig. 1). Due to $95.5 \%$ missing data on ACR in the hospital records, impaired kidney function during the hospital stay was described as eGFR CKD-EPI $<60 \mathrm{ml} /$ $\mathrm{min} / 1.73 \mathrm{~m}^{2}$ at hospital admission or at discharge or any episode of AKI. AKI during the index hospital stay was defined as $\mathrm{SCr}$ increase of $\geq 0.3 \mathrm{mg} / \mathrm{dl}$ within $48 \mathrm{~h}$ or SCr increase of $1.5-1.99 \times$ baseline $\mathrm{SCr}$ within 7 days (KDIGO AKI stage 1), SCr-increase of 2.0-2.9× baseline $\mathrm{SCr}$ (stage 2) and $\mathrm{SCr}$-increase $\geq 3.0 \times$ baseline or
$\mathrm{SCr}>4 \mathrm{mg} / \mathrm{dl}$ or dialysis (stage 3) [25]. A binary variable CKD at the study visit was defined as all CKD-G stages G3a and higher and CKD stages G1A3, G2A2, G2A3 (i.e., largely preserved GFR but significant albuminuria).

\section{Outcome (awareness)}

The fact that CKD or AKI was explicitly stated in prominent parts in the discharge letter (diagnoses and/or summary) and the completeness of ICD coding (i.e., correct coding of CKD [ICD-10 codes N18, N19, I12.0, I13) and/or AKI [ICD-10 code N17]) was used to operationalize physician's awareness of kidney disease.

Patients' awareness of CKD was defined as positive response to the first question of the kidney module: "Have you ever been told by a doctor/health care provider that your kidney function is impaired, e.g. not as good as it would be expected?".

\section{Covariates}

During the index hospital stay the following risk factors were defined: history of heart failure (according to case history or echocardiographic findings of cardiac dysfunction at admission); cardiovascular risk factors known at admission or reported in the discharge letter as hypertension, dyslipidemia, diabetes, smoking and obesity (BMI $\geq 30 \mathrm{~kg} / \mathrm{m}^{2}$ at admission or explicitly stated in the discharge letter). Definitions of risk factors at the study visit were as follows: hypertension (blood pressure $\geq 140 / 90 \mathrm{mmHg}, \geq 140 / 85 \mathrm{mmHg}$ in diabetes, $\geq 150 / 90 \mathrm{mmHg}$ in patients $>80$ yrs., $\geq 130 / 90 \mathrm{mmHg}$ in patients with CKD [26]), diabetes (self-reported

\begin{tabular}{|c|c|c|c|c|c|}
\hline \multirow[b]{2}{*}{$\begin{array}{l}\text { CKD- } \\
\text { stage }\end{array}$} & \multirow[b]{2}{*}{$\begin{array}{l}\text { eGFR } \\
\left(\mathrm{ml} / \mathrm{min} / 1.73 \mathrm{~m}^{2}\right)\end{array}$} & \multicolumn{3}{|c|}{ Albuminuria (ACR) } & \multirow[t]{2}{*}{ Total } \\
\hline & & $\begin{array}{c}\text { A1 } \\
(<30 \mathrm{mg} / \mathrm{g})\end{array}$ & $\begin{array}{c}\text { A2 } \\
(30-300 \mathrm{mg} / \mathrm{g})\end{array}$ & $\begin{array}{c}\text { A3 } \\
(>300 \mathrm{mg} / \mathrm{g})\end{array}$ & \\
\hline G1 & $\geq 90$ & $\begin{array}{c}79 \\
15.2 \%\end{array}$ & $\begin{array}{c}9 \\
1.7 \%\end{array}$ & $\begin{array}{c}2 \\
0.4 \%\end{array}$ & $\begin{array}{c}90 \\
17.3 \%\end{array}$ \\
\hline G2 & $60-89$ & $\begin{array}{c}257 \\
49.4 \%\end{array}$ & $\begin{array}{c}36 \\
6.9 \%\end{array}$ & $\begin{array}{c}10 \\
1.9 \%\end{array}$ & $\begin{array}{c}303 \\
58.3 \%\end{array}$ \\
\hline G3a & $45-59$ & $\begin{array}{c}76 \\
14.6 \%\end{array}$ & $\begin{array}{c}17 \\
3.3 \%\end{array}$ & $\begin{array}{c}3 \\
0.6 \%\end{array}$ & $\begin{array}{c}96 \\
18.5 \%\end{array}$ \\
\hline G3b & $30-44$ & $\begin{array}{c}15 \\
2.9 \% \\
\end{array}$ & $\begin{array}{c}5 \\
1.0 \% \\
\end{array}$ & $\begin{array}{c}2 \\
0.4 \% \\
\end{array}$ & $\begin{array}{c}22 \\
4.2 \% \\
\end{array}$ \\
\hline G4 & $15-29$ & $\begin{array}{c}3 \\
0.6 \% \\
\end{array}$ & $\begin{array}{c}2 \\
0.4 \% \\
\end{array}$ & $\begin{array}{c}3 \\
0.6 \% \\
\end{array}$ & $\begin{array}{c}8 \\
1.5 \% \\
\end{array}$ \\
\hline G5 & $<15$ & 0 & 0 & $\begin{array}{c}1 \\
0.2 \% \\
\end{array}$ & $\begin{array}{c}1 \\
0.2 \% \\
\end{array}$ \\
\hline \multicolumn{2}{|l|}{ total } & $\begin{array}{c}430 \\
82.7 \% \\
\end{array}$ & $\begin{array}{c}69 \\
13.3 \%\end{array}$ & $\begin{array}{c}21 \\
4.0 \% \\
\end{array}$ & $\begin{array}{c}520 \\
100 \%\end{array}$ \\
\hline
\end{tabular}

Fig. 1 Stages of CKD according to eGFR and albuminuria following KDIGO classification; displayed are number of patients (\%) within each category. The color code indicates risk category according to KDIGO [24]: green "low risk", yellow "moderate risk", orange "high risk" and red "very high risk" 
diabetes or impaired fasting glucose or impaired glucose tolerance), dyslipidemia (LDL cholesterol $\geq 2.5 \mathrm{mmol} / \mathrm{L}$ ), obesity (body mass index $[\mathrm{BMI}] \geq 30 \mathrm{~kg} / \mathrm{m}^{2}$ ) and smoking (self-reported, or CO in exhaled air >10 ppm [20]).

\section{Statistical methods}

Data are reported as proportions and median (interquartile range, IQR) and were compared across categories of interest (i.e. impaired kidney function during hospital stay, CKD at study visit) using Wilcoxon ranksum test, Kruskal-Wallis test and $\chi^{2}$ test/Fisher's exact test, as appropriate. The trend of patient's awareness, referral to specialist and visit at the specialist across CKD-G stages was analyzed by Cochran-MantelHaenszel test. Determinants of patients' awareness of $C K D$ (i.e. positive response to the first question of the kidney module: "Have you ever been told by a doctor/ health care provider that your kidney function is impaired, e.g. not as good as it would be expected?") and the fact that CKD or AKI were mentioned in the hospital discharge letter (physician's awareness of kidney disease) in all participants were investigated by univariable and multivariable logistic regression, using backwards selection including variables statistically significant in univariate analysis. Results are displayed as odds ratio (OR) with respective $95 \%$ confidence intervals (CI). Analyses were performed on a complete case dataset, i.e. $n=474$ with data on the kidney module. We tested the robustness of the multivariable models on a dataset with imputed missing data, using five imputations derived from the Markov Chain Monte Carlo method (SAS proc. mi). We also performed sensitivity analyses in which eGFR $<50 \mathrm{ml} / \mathrm{min} / 1.73 \mathrm{~m}^{2}$ was used rather than $<60 \mathrm{ml} / \mathrm{min} / 1.73 \mathrm{~m}^{2}$ to increase the confidence in the patient suffering from true kidney disease by excluding patients with only a minor variation in $\mathrm{SCr}$ that made their eGFR values being slightly below $60 \mathrm{ml} / \mathrm{min} / 1.73 \mathrm{~m}^{2}$. Analyses were performed using SAS 9.3 (SAS Institute Inc., Cary, NC, USA). Two-sided $p$-values $<0.05$ were considered statistically significant.

\section{Results}

Prevalence of impaired kidney function during the (index) hospital stay

A total of 536 German patients were enrolled in EUROASPIRE IV (median age at the index hospital stay 67 years, $82 \%$ male). Median SCr at hospital admission for the index CHD event (i.e. first measurement in patient record) was 0.9 (IQR $0.8 ; 1.1) \mathrm{mg} / \mathrm{dl}$, reflecting an eGFR $_{\text {admission }}$ of $81.1(66.2 ; 93.3) \mathrm{ml} / \mathrm{min} / 1.73 \mathrm{~m}^{2}$ and 94 patients $(17.6 \%)$ had eGFR $<60 \mathrm{ml} / \mathrm{min} / 1.73 \mathrm{~m}^{2}$. At hospital discharge (i.e. last measurement in patient record), median $\mathrm{SCr}$ was $1.0(0.8 ; 1.1) \mathrm{mg} / \mathrm{dl}$, median eGFR $_{\text {discharge }}$ was $78.7(64.1 ; 91.4) \mathrm{ml} / \mathrm{min}$ and 100
(18.1\%) patients had eGFR $<60 \mathrm{ml} / \mathrm{min} / 1.73 \mathrm{~m}^{2}$. AKI was observed in 94 (18.1\%) subjects. Most AKI episodes represented a slight increase of SCr (AKI stage 1: $89.4 \%$ ), while a rise in $\mathrm{SCr}$ of not more than exactly $0.3 \mathrm{mg} / \mathrm{dl}$ was observed in 16 patients. Two events were of AKI stage $2(2.1 \%)$ and $8(8.5 \%)$ were of stage 3, of which 3 had to be treated by acute hemodialysis. Any impairment in kidney function during the hospital stay (either eGFR $<60 \mathrm{ml} / \mathrm{min} / 1.73 \mathrm{~m}^{2}$ at admission, or at discharge or AKI) was observed in 172 patients (32.2\%). Patients with impaired kidney function were older, more often had a history of heart failure, had a longer duration of $\mathrm{CHD}$, and were more likely to receive CABG during the hospital stay. The hospital stay was on average also longer in CKD patients as compared to patients without renal impairment (Table 1). No differences in classic CV risk factors were observed. In the sensitivity analysis applying the lower eGFR cut-off, we found 38 (7.1\%) subjects with eGFR $<50 \mathrm{ml} / \mathrm{min} /$ $1.73 \mathrm{~m}^{2}$ at hospital admission, $n=46(8.7 \%)$ at hospital discharge and any impairment of kidney function during the hospital stay in $n=119$ (22.3\%) patients. We did not find any meaningful differences in the patient characteristics as compared to results using the eGFR $60 \mathrm{ml} / \mathrm{min} / 1.73 \mathrm{~m}^{2}$ cut-off (detailed data not shown).

\section{Physician's awareness of kidney disease during the (index) hospital stay}

Of the 474 patients in whom data on the kidney module were available (see Methods), CKD and/or AKI were reported in prominent sections of the hospital discharge letter in $37(7.8 \%)$ of all patients and in 32 (21.5\%) of patients with impaired kidney function. While older age, length of hospital stay, diabetes and obesity lost their association in multivariable modeling, worse kidney function at hospital discharge (OR $_{\text {eGFR }}$ 0.92 [95\% CI $0.89 ; 0.94]$ ) and more severe episodes of AKI (OR 93 [10; 848]) remained independently related to physician's awareness of kidney disease. Moreover, in patients in whom the index event was the primary diagnosis of CHD, it was less likely (OR 0.38 [0.14; 1.00]) that impaired kidney function was mentioned in the discharge letter (Table 2). In sensitivity analyses, these findings were similar when imputing the missing values (data not shown).

Of patients admitted to the University Hospital Würzburg $(n=498)$ that had CKD or experienced AKI during the index hospital stay $(n=162)$, relevant ICD codes were applied to 117 (72.2\%) patients after discharge. Correct coding was particularly observed in those patients with more severe stages of AKI $(100 \%$ in stage $2,75 \%$ in stage 3 ) and CKD (76.9\% in stage G3a, $95.2 \%$ in G3b, $100 \%$ in G4 and $100 \%$ in G5). 
Table 1 Patient's characteristics during the EUROASPIRE IV index hospital stay by impaired kidney function

\begin{tabular}{|c|c|c|c|}
\hline & $\begin{array}{l}\text { Normal kidney function } \\
n=362(67.8 \%)\end{array}$ & $\begin{array}{l}\text { Impaired kidney function } \\
n=172(32.2 \%)\end{array}$ & $p$-value \\
\hline Age, years & $64.0(58.5 ; 70.4)$ & $72.0(65.7 ; 75.1)$ & $<0.001$ \\
\hline Male sex & $301(83.2 \%)$ & $139(80.8 \%)$ & 0.51 \\
\hline Length of hospital stay (days) & $3(1 ; 7)$ & $8(3 ; 11)$ & $<0.001$ \\
\hline \multicolumn{4}{|l|}{ Details of CHD event during index hospital stay } \\
\hline AMl, any & $128(35.5 \%)$ & $75(43.6 \%)$ & 0.07 \\
\hline NSTEMI & $53(41.4 \%)$ & $33(44.0 \%)$ & \multirow[t]{3}{*}{0.26} \\
\hline STEMI & $60(46.9 \%)$ & $28(37.3 \%)$ & \\
\hline Unclear/missing & $15(11.7 \%)$ & $14(18.7 \%)$ & \\
\hline \multicolumn{3}{|l|}{ Therapy (max.) } & \multirow[t]{4}{*}{$<0.001$} \\
\hline Conservative (no intervention) & $54(14.9 \%)$ & $29(16.9 \%)$ & \\
\hline $\mathrm{PCl} /$ stent & $279(77.1 \%)$ & $88(51.2 \%)$ & \\
\hline CABG & $29(8.0 \%)$ & $55(32.0 \%)$ & \\
\hline \multicolumn{4}{|l|}{ CHD history } \\
\hline Index event as the primary diagnosis of $\mathrm{CHD}$ & $162(44.8 \%)$ & $64(37.2 \%)$ & 0.10 \\
\hline \multicolumn{4}{|l|}{ In those with h/o CHD } \\
\hline Duration of CHD, yrs. & $1.4(0.4 ; 9.0)$ & $5.9(0.6 ; 16.3)$ & $<0.01$ \\
\hline CABG (prior to index) & $35(17.5 \%)$ & $21(19.4 \%)$ & 0.67 \\
\hline $\mathrm{PCl} /$ stent (prior to index) & $101(50.5 \%)$ & $55(50.9 \%)$ & 0.94 \\
\hline MI (prior to index) & $125(62.5 \%)$ & $65(60.2 \%)$ & 0.69 \\
\hline History of heart failure ${ }^{a}$ & $117(32.7 \%)$ & $82(48.0 \%)$ & $<0.001$ \\
\hline \multicolumn{4}{|l|}{ Classic cardiovascular risk factors } \\
\hline Diabetes $^{\mathrm{b}}$ & $98(27.2 \%)$ & $51(30.2 \%)$ & 0.47 \\
\hline Hypertension $^{\text {b }}$ & $299(84.2 \%)$ & $142(86.6 \%)$ & 0.48 \\
\hline Hyperlipidemia ${ }^{\text {b }}$ & $237(67.1 \%)$ & $112(70.0 \%)$ & 0.52 \\
\hline Smoking $^{b}$ & $76(22.8 \%)$ & $28(18.9 \%)$ & 0.33 \\
\hline Obesity ${ }^{c}$ & $145(41.1 \%)$ & 75 (47.5\%) & 0.18 \\
\hline \multicolumn{4}{|l|}{ Kidney function } \\
\hline $\mathrm{SCr}$ at admission ${ }^{d}, \mathrm{mg} / \mathrm{dl}$ & $0.9(0.8 ; 1.0)$ & $1.2(0.9 ; 1.3)$ & $<0.001$ \\
\hline eGFR at admission, $\mathrm{ml} / \mathrm{min} / 1.73 \mathrm{~m}^{2}$ & $86.3(74.9 ; 96.3)$ & $59.2(51.3 ; 80.5)$ & $<0.001$ \\
\hline $\mathrm{SCr}$ at discharge ${ }^{\mathrm{e}}, \mathrm{mg} / \mathrm{dl}$ & $0.9(0.8 ; 1.0)$ & $1.2(1.0 ; 1.4)$ & $<0.001$ \\
\hline eGFR at discharge, $\mathrm{ml} / \mathrm{min} / 1.73 \mathrm{~m}^{2}$ & $85.2(74.6 ; 93.8)$ & $57.5(49.0 ; 73.8)$ & $<0.001$ \\
\hline
\end{tabular}

Data are $\mathrm{n}(\%)$, median (inter quartile range), analyses restricted to patients without missing values in respective variables

Abbreviations: $C H D$ coronary heart disease, $C A B G$ coronary artery bypass grafting, $P C l$ percutaneous coronary intervention, $M I$ myocardial infarction, $A M I$ acute myocardial infarction, STEMI ST-elevation myocardial infarction, NSTEMI non-ST-elevation myocardial infarction, SCr serum creatinine, eGFR estimated glomerular filtration rate

${ }^{a}$ Known at hospital admission or echocardiographic findings of cardiac dysfunction

${ }^{\mathrm{b}}$ Known at hospital admission or stated in discharge letter

${ }^{c}$ Body mass index $\geq 30 \mathrm{~kg} / \mathrm{m}^{2}$ at hospital admission or stated in discharge letter

${ }^{d}$ First measurement in patient record

e Last measurement in patient record

\section{Prevalence of chronic kidney disease at the study visit}

The study visit was performed on average 1.8 years (1.1; 2.5) after the index hospital stay. At the study visit, 530 of the 536 German patients had $\mathrm{SCr}$ values available, with a median of $1.0(0.9 ; 1.2) \mathrm{mg} / \mathrm{dl}$ reflecting an eGFR of $74.1(60.0 ; 85.3) \mathrm{ml} / \mathrm{min} / 1.73 \mathrm{~m}^{2}$. ACR was measured in 526 subjects $(98.1 \%)$, with a median of $4.9(1.3 ; 15.8)$ $\mathrm{mg} / \mathrm{g}$. One patient was on chronic hemodialysis treatment (started already prior to the index-hospital stay). According to KDIGO classification of CKD (Fig. 1), 127 (24.4\%) individuals had eGFR $<60 \mathrm{ml} / \mathrm{min} / 1.73 \mathrm{~m}^{2}$ and another 48 subjects (9.2\%) had largely preserved eGFR but significant albuminuria (i.e. stages G1A3, G2A2, G2A3). Patients with CKD were more likely to be older, with a longer duration of CHD and a history of CABG, heart failure and peripheral artery disease 
Table 2 Determinants of physician's awareness of kidney disease a at the EUROASPIRE IV index hospital stay (logistic regression)

\begin{tabular}{|c|c|c|c|c|}
\hline & \multicolumn{2}{|l|}{ Univariable } & \multicolumn{2}{|l|}{ Multivariable ${ }^{b}$} \\
\hline & OR $(95 \% \mathrm{Cl})$ & $p$-value & OR $(95 \% \mathrm{Cl})$ & $p$-value \\
\hline Patient's age (index) [per year] & $1.06(1.01 ; 1.11)$ & $<0.01$ & $0.98(0.92 ; 1.04)$ & 0.56 \\
\hline Patient's sex [male vs. female] & $1.10(0.44 ; 2.72)$ & 0.84 & - & - \\
\hline Length of hospital stay $[\log (d)]$ & $1.58(1.15 ; 2.18)$ & $<0.01$ & $1.25(0.83 ; 1.89)$ & 0.29 \\
\hline Therapy (max.) [vs. no intervention)] & & 0.10 & - & - \\
\hline \multicolumn{5}{|l|}{$\mathrm{PCl} /$ stent vs. conservative } \\
\hline \multirow[t]{2}{*}{ CABG vs. conservative } & $0.49(0.21 ; 1.12)$ & & & \\
\hline & $1.07(0.39 ; 2.96)$ & & & \\
\hline AMI during hospital stay & $1.49(0.76 ; 2.94)$ & 0.24 & - & - \\
\hline Index hospital stay as primary CHD event [yes vs. no] & $0.32(0.14 ; 0.75)$ & $<0.01$ & $0.38(0.14 ; 1.00)$ & 0.05 \\
\hline History of $\mathrm{CHF}^{\mathrm{C}}$ & $1.12(0.56 ; 2.21)$ & 0.76 & - & - \\
\hline \multicolumn{5}{|l|}{ Cardiovascular risk factors } \\
\hline Diabetes $^{\mathrm{d}}$ (index) & $2.57(1.30 ; 5.07)$ & $<0.01$ & $1.85(0.77 ; 4.44)$ & 0.17 \\
\hline Hypertension ${ }^{d}$ (index) & $2.12(0.63 ; 7.09)$ & 0.22 & - & - \\
\hline Hyperlipidemia (index) & $2.21(0.95 ; 5.17)$ & 0.07 & - & - \\
\hline Smoking (index) ${ }^{d}$ & $0.35(0.10 ; 1.16)$ & 0.08 & - & - \\
\hline Obesity $^{\mathrm{e}}$ (index) & $2.23(1.11 ; 4.48)$ & 0.02 & $1.34(0.58 ; 3.11)$ & 0.49 \\
\hline \multicolumn{5}{|l|}{ Kidney function } \\
\hline eGFR at discharge $\left[\right.$ per $\left.\mathrm{ml} / \mathrm{min} / 1.73 \mathrm{~m}^{2}\right]$ & $0.93(0.91 ; 0.95)$ & $<0.001$ & $0.92(0.89 ; 0.94)$ & $<0.001$ \\
\hline AKl-stages $[\mathrm{vs} . n o \mathrm{AKI}]^{f}$ & & $<0.001$ & & $<0.001$ \\
\hline Stage 1 [vs. no AKI] & $1.51(0.59 ; 3.85)$ & & $0.38(0.12 ; 1.22)$ & \\
\hline Stage 2/3 [vs. no AKI] & $54.7(10.8 ; 277.7)$ & & $92.7(10.1 ; 847.9)$ & \\
\hline
\end{tabular}

Data are odds ratio (OR) with respective $95 \%$ confidence interval $(\mathrm{Cl})$ and $\mathrm{p}$-value

Abbreviations: $C H D$ coronary heart disease, $C A B G$ coronary artery bypass grafting, $P C I$ percutaneous coronary intervention, eGFR estimated glomerular filtration rate, $A K I$ acute kidney injury, $C K D$ chronic kidney disease

${ }^{a}$ CKD and or AKI explicitly mentioned (diagnoses, summary) in the discharge letter of the index hospital stay; analyses based on $n=474$ patients in whom data on the kidney module were available (see Methods)

${ }^{\mathrm{b}}$ Multivariable model of backward selection, included are variables with significant $(p<0.05)$ association in univariable analysis; $\mathrm{p}$ for exclusion 0.05 ;

non-significant associations displayed italic with OR $(95 \% \mathrm{Cl})$ and $p$-value when variable left the model. Order of exclusion: (1) age; (2) obesity;

(3) length of hospital stay; (4) diabetes

'Known at hospital admission or echocardiographic findings of cardiac dysfunction

${ }^{\mathrm{d} K n o w n}$ at hospital admission or stated in discharge letter

${ }^{e}$ Body mass index $\geq 30 \mathrm{~kg} / \mathrm{m}^{2}$ at hospital admission or stated in discharge letter

${ }^{f} \mathrm{SCr}$ increase of $\geq 0.3 \mathrm{mg} / \mathrm{dl}$ within $48 \mathrm{~h}$ or SCr-increase of $1.5-1.99 \times$ baseline $\mathrm{SCr}$ within 7 days (stage 1 ), SCr-increase of $2.0-2.9 \times$ baseline SCr (stage 2 )

and $\mathrm{SCr}$-increase $\geq 3.0 \times$ baseline or $\mathrm{SCr}>4 \mathrm{mg} / \mathrm{dl}$ or dialysis (stage 3 )

(Table 3). Classic risk factors such as hypertension, diabetes, dyslipidemia and overweight/obesity were also more common in subjects with impaired kidney function, whereas smoking was less prevalent in CKD patients. Primary care regarding CHD was reported to be provided by a cardiologist in $111(60 \%)$ patients with CKD, which on average also had spent a shorter time in education. In those patients, impaired kidney function was reported more frequently in the discharge letter of the index hospital stay. The sensitivity analysis using the eGFR $<50 \mathrm{ml} / \mathrm{min} / 1.73 \mathrm{~m}^{2}$ cut-off identified 65 patients (12.3\%). Again, the differences in patient characteristics between of those subjects with more advanced CKD as compared to those with normal kidney function were overall very similar (detailed data not shown) to the results derived from the results presented above (Table 3).
Patients' awareness of chronic kidney disease at the study visit

Data on patient awareness were part of the kidney module at the German study center and were thus available in $n=474$ participants (see Methods). Of those 158 subjects with CKD, 54 (34.2\%) patients reported that they had been told about chronic kidney disease, 23 (14.6\%) were referred to a renal specialist and $21(13.3 \%)$ had been seen by a specialist. Even in those without overt renal dysfunction at the study visit, 19 (5.5\%) reported to be aware of impaired kidney function, 11 (3.2\%) were referred and $12(3.5 \%)$ were seen by a specialist. Overall, greater proportions of awareness, referral or specialist care were observed in more advanced stages of kidney disease ( $\mathrm{p}$ for trend $<0.01$ ), however, based on a limited number of observations (Table 4). Accordingly, reduced 
Table 3 Patient characteristics at the EUROASPIRE IV study visit by chronic kidney disease ${ }^{a}$

\begin{tabular}{|c|c|c|c|}
\hline & $\begin{array}{l}\text { normal kidney function } \\
n=345(65.1 \%)\end{array}$ & $\begin{array}{l}\text { chronic kidney disease } \\
n=185(34.9 \%)\end{array}$ & $p$-value \\
\hline Age, yrs & $65.4(59.6 ; 72.2)$ & $73.4(66.5 ; 77.0)$ & $<0.001$ \\
\hline Male gender & $291(84.4 \%)$ & $145(78.4 \%)$ & 0.09 \\
\hline Total year in education, yrs & $12(11 ; 15)$ & $11(11 ; 14)$ & $<0.001$ \\
\hline Education level (higher vs. lower levels ${ }^{b}$ ) & $72(20.9 \%)$ & $27(14.6 \%)$ & 0.08 \\
\hline \multicolumn{4}{|l|}{ History of CHD } \\
\hline Duration of CHD & $2.7(1.9 ; 6.4)$ & $3.4(2.0 ; 12.9)$ & $<0.01$ \\
\hline \multicolumn{4}{|l|}{ CHD history } \\
\hline$-C A B G$ & $77(22.3 \%)$ & $59(31.9 \%)$ & 0.02 \\
\hline - PCl/stent & $278(78.6 \%)$ & $138(74.6 \%)$ & 0.12 \\
\hline - AMI & $131(38.0 \%)$ & $49(42.7 \%)$ & 0.30 \\
\hline History of heart failure & $40(11.6 \%)$ & $38(20.7 \%)$ & $<0.01$ \\
\hline History of stroke & $33(9.8 \%)$ & $22(11.9 \%)$ & 0.45 \\
\hline History of peripheral artery disease & $18(5.2 \%)$ & $29(15.7 \%)$ & $<0.001$ \\
\hline \multicolumn{4}{|l|}{ Classic CV risk factors } \\
\hline BMI $\left[\mathrm{kg} / \mathrm{m}^{2}\right]$ & $28.0(25.9 ; 30.7)$ & $29.5(27.0 ; 32.8)$ & $<0.001$ \\
\hline Overweight (BMI $\geq 25$ ) & $281(82.2 \%)$ & $168(91.3 \%)$ & $<0.01$ \\
\hline Obesity (BMI 30) & $105(30.7 \%)$ & $86(46.7 \%)$ & $<0.001$ \\
\hline \multicolumn{4}{|l|}{ Blood pressure } \\
\hline Systolic & $133(122 ; 148)$ & $138(128 ; 152)$ & $<0.01$ \\
\hline Diastolic & $80(73 ; 87)$ & $81(73 ; 88)$ & 0.67 \\
\hline Hypertension $^{c}$ & $142(41.2 \%)$ & $96(52.2 \%)$ & 0.02 \\
\hline LDL-cholesterol (mmol/l) & $2.59(2.16 ; 3.14)$ & $2.43(1.98 ; 2.98)$ & 0.02 \\
\hline \multicolumn{4}{|l|}{ Hyperlipidemia } \\
\hline LDL cholesterol $\geq 2.5 \mathrm{mmol} / \mathrm{l}$ & $188(56.1 \%)$ & $77(45.6 \%)$ & 0.03 \\
\hline LDL cholesterol $\geq 1.8 \mathrm{mmol} / \mathrm{l}$ & $307(91.6 \%)$ & $143(84.6 \%)$ & 0.02 \\
\hline Diabetes $^{\mathrm{d}}$ & $70(20.5 \%)$ & $75(41.4 \%)$ & $<0.001$ \\
\hline Smoking ${ }^{e}$ & $49(14.2 \%)$ & $14(7.6 \%)$ & 0.02 \\
\hline \multicolumn{4}{|l|}{ Chronic kidney disease } \\
\hline $\mathrm{SCr}_{\text {study-visit }}(\mathrm{mg} / \mathrm{dl})$ & $1.0(0.8 ; 1.0)$ & $1.2(1.1 ; 1.4)$ & $<0.001$ \\
\hline eGFR $R_{\text {CKD-EPI }}\left(\mathrm{ml} / \mathrm{min} / 1.73 \mathrm{~m}^{2}\right)$ & $81.0(71.2 ; 90.4)$ & $53.9(46.6 ; 62.6)$ & $<0.001$ \\
\hline$A C R_{\text {study-visit }}(\mathrm{mg} / \mathrm{g})$ & $2.9(0 ; 7.4)$ & $20.4(5.0 ; 78.5)$ & $<0.001$ \\
\hline $\begin{array}{l}\text { Information on impaired kidney function } \\
\text { in a discharge letter of a hospital stay due to } \mathrm{CHD}^{f}\end{array}$ & $6(1.9 \%)$ & $31(19.0 \%)$ & $<0.001$ \\
\hline
\end{tabular}

Data are $\mathrm{n}(\%)$, median (inter quartile range), analyses restricted to patients without missing values in respective variables

Abbreviations: $C H D$ coronary heart disease, $C A B G$ coronary artery bypass grafting, $P C I$ percutaneous coronary intervention, $A M I$ acute myocardial infarction, $B M I$ body mass index, $L D L$ low density lipoprotein, $S C r$ serum creatinine, eGFR estimated glomerular filtration rate, $A C R$ urinary albumin/creatinine ratio

${ }^{\mathrm{a}} \mathrm{CKD}$ (stages CKD-G3 and higher, G2A2, G2A3, G1A3) vs. normal kidney function (G1A1, G1A2, G2A1)

${ }^{b}$ Higher (intermediate between secondary level and university [e.g. technical training], College/University completed, post graduate degree) vs. lower levels of education

${ }^{C}$ As recommended by the German Society of Cardiology as blood pressure $\geq 140 / 90 \mathrm{mmHg}, \geq 140 / 80 \mathrm{mmHg}$ in patients with diabetes, $\geq 140 / 85 \mathrm{mmHg}$ in

diabetes, $\geq 150 / 90 \mathrm{mmHg}$ in patients $>80$ years, $\geq 130 / 90 \mathrm{mmHg}$ in patients with CKD

dSelf-reported diabetes or impaired fasting glucose/impaired glucose tolerance

eself-reported or CO >10 ppm

EUROASPIRE IV index hospital stay

kidney function $\left(\mathrm{OR}_{\mathrm{eGFR}} 0.94[0.92 ; 0.96]\right)$ was also related to an increased level of patient's awareness of CKD in multivariable logistic regression, aside from a history of heart failure (OR 1.99 [1.00; 3.97]), obesity (OR 1.97
[1.07; 3.64]), and the fact that renal impairment was reported in the index discharge letter (OR 5.51 [2.35; 12.9]) (Table 5). Similar results emerged from analyses of the imputed dataset. 
Table 4 Patient's awareness of CKD at the EUROASPIRE IV study visit and specialist care by stages of CKD

\begin{tabular}{|c|c|c|c|c|c|c|c|c|}
\hline & \multicolumn{8}{|c|}{ CKD G stages at EUROASPIRE IV study visit ${ }^{a}$} \\
\hline & \multicolumn{2}{|l|}{ G1 } & \multicolumn{2}{|l|}{ G2 } & \multirow{2}{*}{$\begin{array}{l}\text { G3a } \\
(n=83)\end{array}$} & \multirow{2}{*}{$\begin{array}{l}\mathrm{G} 3 \mathrm{~b} \\
(n=18)\end{array}$} & \multirow{2}{*}{$\begin{array}{l}\mathrm{G} 4 \\
(n=7)\end{array}$} & \multirow{2}{*}{$\begin{array}{l}\mathrm{G} 5 \\
(n=1)\end{array}$} \\
\hline & $\begin{array}{l}\text { All patients } \\
(n=84)\end{array}$ & $\begin{array}{l}\text { Patients with impaired } \\
\text { kidney function }{ }^{b} \\
(n=1)\end{array}$ & $\begin{array}{l}\text { All patients } \\
(n=275)\end{array}$ & $\begin{array}{l}\text { Patients with impaired } \\
\text { kidney function }{ }^{\mathrm{b}} \\
(n=47)\end{array}$ & & & & \\
\hline $\begin{array}{l}\text { Ever been told by a doctor } \\
\text { about impaired kidney function }\end{array}$ & $2(2.4 \%)$ & 0 & $24(8.7 \%)$ & $7(14.9 \%)$ & $33(39.8 \%)$ & 7 (38.9\%) & $6(85.7 \%)$ & $1(100 \%)$ \\
\hline $\begin{array}{l}\text { Recommendation to seek } \\
\text { professional advice/referred } \\
\text { to kidney specialist }{ }^{\complement}\end{array}$ & $1(1.2 \%)$ & 0 & $12(4.4 \%)$ & $2(4.3 \%)$ & $11(13.3 \%)$ & $5(27.8 \%)$ & $4(57.1 \%)$ & $1(100 \%)$ \\
\hline Seen by a kidney specialist ${ }^{c}$ & $1(1.2 \%)$ & 0 & $13(4.7 \%)$ & 2 (4.3\%) & 9 (10.8\%) & 4 (22.2\%) & 5 (71.4\%) & $1(100 \%)$ \\
\hline
\end{tabular}

Data are $\mathrm{n}$ (\% proportions within each category) based on a total of $n=474$ patients in whom data on the kidney module were available (see Methods). $P$-value for comparison across all categories

Abbreviations: CKD chronic kidney disease

${ }^{a}$ CKD G stages according to KDIGO based on eGFR replacement therapy

${ }^{b}$ Definition based on eGFR $R_{C K D-E P I}$ and urinary albumin/creatinine (ACR) ratio; KDIGO-stages G1A1, G1A2 and G2A1 considered as normal kidney function, whereas G1A3, G2A2, G2A3 and more severe G-stages are considered as chronic kidney disease (CKD) (see Methods)

'Specialist care, e.g. by nephrology, urology

\section{Discussion}

In our population of German CHD patients enrolled in EUROASPIRE IV, about one third of patients in considerably stable conditions at the study visit had CKD, but only a third of those reported that they had been told about renal impairment. A substantial proportion of patients experienced AKI (18\%) during a hospital stay for $\mathrm{CHD}$ and/or was discharged with compromised kidney function (18\%). Yet, the discharge letter of these patients prominently mentioned chronic or acute kidney disease only in $20 \%$. In contrast, correct ICD coding of CKD or AKI, which is relevant for reimbursement, was more complete but still suboptimal.

Awareness of CKD among CHD patients with kidney disease Although CKD is common and associated with worse prognosis, only a small proportion of patients $(<5-30 \%)$ are aware of their disease in population-based studies $[14,27]$, CKD cohorts [15, 28] and in CHD patients [21]. Despite public education programs e.g. in the US or the UK, only little improvement in CKD awareness could be observed [17, 29]. Early diagnosis is needed to inform patients about their disease and initiate appropriate treatment [30]. Patient education should be expected to improve adherence to medication and treatment targets $[16,31]$, but data in CKD are conflicting. Patients on renal replacement therapy (RRT) with adequate knowledge about their disease and treatment targets including dietary restrictions have a lower mortality risk when compared to less educated patients [32]. In contrast, in earlier stages of CKD, achievement of treatment targets for adequate blood pressure control was not significantly associated with the level of patient's awareness of CKD [17]. Yet, recent data are encouraging that focused education of the primary care physician (PCP) and the patient including his relatives can indeed improve risk factor control and also slow the progression rate of CKD [33]. As directly from the patent's perspective, it seems intuitive that one feels more confident if he is aware of a certain condition and is informed and educated accordingly about the treatment options. On the other hand, he might also be frightened by the information on the diagnosis and the disease's prognosis [31], which may aggravate depressive mood, since depression is a common comorbidity in CHD [34] as well as in CKD [35]. Specialist care, e.g. provided by a nephrologist, may help to adequately inform patients about their individual risk for CKD progression [13], and thus help individualizing the therapeutic strategy and treatment targets. It has been shown that (early) referral to nephrology care can slow CKD progression and is associated with reduced mortality risk once RRT is initiated [36, 37].

In our sample of stable CHD patients, we found $24 \%$ with CKD (i.e., applying the commonly used cut-off of eGFR $<60 \mathrm{ml} / \mathrm{min} / 1.73 \mathrm{~m}^{2}$ ), which is nearly 10 -times higher than in recent numbers of the German general population [38]. Another $10 \%$ of our sample had albuminuria with preserved eGFR representing those at risk for CKD progression [24, 39]. Of those with CKD, only about a third were aware of their disease and only a minority was being seen by nephrologists, however, with higher likelihood of CKD awareness and specialist care in more severe stages of CKD. The latter observation, however, is based on very few data in the respective categories and need to be interpreted with caution. We could not find significant associations with CKD awareness with the level of education, gender, or diabetic status. Yet, a history of heart failure was related to a higher level of CKD awareness, independently of the severity of CKD. This might be explained by frequent appointments 
Table 5 Determinants of patient's awareness of CKDa at the EUROASPIRE IV study visit (logistic regression)

\begin{tabular}{|c|c|c|c|c|}
\hline & \multicolumn{2}{|l|}{ Univariable } & \multicolumn{2}{|l|}{ Multivariable ${ }^{b}$} \\
\hline & $\mathrm{OR}(95 \% \mathrm{Cl})$ & $P$ & $\mathrm{OR}(95 \% \mathrm{Cl})$ & $P$ \\
\hline Age, $[/ y r]$ & $1.05(1.02 ; 1.08)$ & $<0.01$ & $0.97(0.93 ; 1.01)$ & 0.18 \\
\hline Male gender [vs. female] & $0.59(0.33 ; 1.07)$ & 0.08 & - & \\
\hline \multicolumn{5}{|l|}{ Education } \\
\hline Total years $[/ \log (y r)]$ & $0.65(0.28 ; 1.50)$ & 0.32 & - & \\
\hline Higher vs. lower levels ${ }^{c}$ & $0.57(0.27 ; 1.20)$ & 0.14 & - & \\
\hline $\begin{array}{l}\text { Information on impaired kidney function in a discharge letter } \\
\text { of a hospital stay due to } \mathrm{CHD}^{\mathrm{d}}\end{array}$ & $15.8(7.45 ; 33.7)$ & $<0.001$ & $5.51(2.35 ; 12.9)$ & $<0.001$ \\
\hline Primary care for CHD provided by cardiologist [vs. non-cardiologist] & $0.88(0.52 ; 1.48)$ & 0.62 & - & - \\
\hline \multicolumn{5}{|l|}{ History of CHD } \\
\hline CHD duration $[/ \log (y r)]$ & $1.30(1.01 ; 1.66)$ & 0.04 & $0.89(0.64 ; 1.23)$ & 0.47 \\
\hline CABG ever & $1.52(0.88 ; 2.63)$ & 0.13 & - & - \\
\hline History of heart failure & $2.43(1.36 ; 4.34)$ & $<0.01$ & $1.99(1.00 ; 3.97)$ & 0.05 \\
\hline History of peripheral artery disease & $2.19(1.07 ; 4.48)$ & 0.03 & $0.83(0.31 ; 2.19)$ & 0.71 \\
\hline Diabetes $^{\mathrm{e}}$ & $1.23(0.71 ; 2.13)$ & 0.45 & - & \\
\hline Smoking $^{f}$ & $0.81(0.37 ; 1.78)$ & 0.60 & - & \\
\hline Dyslipidemia $^{9}$ & $1.37(0.80 ; 2.34)$ & 0.25 & - & \\
\hline Obesity $^{\mathrm{h}}$ & $1.93(1.16 ; 3.21)$ & 0.01 & $1.97(1.07 ; 3.64)$ & 0.03 \\
\hline eGFRRCD_EPI at study visit $\left[/ \mathrm{ml} / \mathrm{min} / 1.73 \mathrm{~m}^{2}\right]$ & $0.93(0.91 ; 0.95)$ & $<0.001$ & $0.94(0.92 ; 0.96)$ & $<0.001$ \\
\hline ACR at study visit $[/ \log (\mathrm{mg} / \mathrm{g})]$ & $1.09(1.01 ; 1.17)$ & 0.02 & $0.99(0.91 ; 1.08)$ & 0.88 \\
\hline
\end{tabular}

Data are odds ratio (OR) with respective $95 \%$ confidence interval $(\mathrm{Cl})$ and $\mathrm{p}$-value

Abbreviations: $C H D$ coronary heart disease, CABG coronary artery bypass grafting, PAD peripheral artery disease, eGFR estimated glomerular filtration rate according to CKD-EPI formula, AKI acute kidney injury, CKD chronic kidney disease

apositive response to "Have you ever been told by a doctor/health care provider that your kidney function is impaired, e.g. not as good as it would be expected?"; analyses based on $n=474$ patients in whom data on the kidney module were available (see Methods)

${ }^{b}$ Multivariable model of backward selection, included are variables with significant $(p<0.05)$ association in univariable analysis; $\mathrm{p}$ for exclusion 0.05 ; nonsignificant associations displayed italic with $\mathrm{OR}(95 \% \mathrm{Cl})$ and $p$-value when variable left the model. Order of exclusion: (1) ACR; (2) history of PAD; (3) duration of CHD; (4) age

CHigher (intermediate between secondary level and university [e.g. technical training], College/University completed, post graduate degree) vs. lower levels of education

${ }^{d}$ EUROASPIRE IV index hospital stay

éself-reported diabetes or impaired fasting glucose/impaired glucose tolerance

fSelf-reported or $\mathrm{CO}>10 \mathrm{ppm}$

${ }^{9} \mathrm{LDL}$-cholesterol $\geq 2.5 \mathrm{mmol} / \mathrm{L}$

hody mass index $\geq 30 \mathrm{~kg} / \mathrm{m}^{2}$

specifically for heart failure and potentially also for cardio-renal syndrome [40] at the cardiologist and the PCP, with an increased likelihood of impaired kidney function being detected, mentioned and discussed during such appointments. Furthermore, we found that patients were more likely to know about impaired kidney function if either CKD or AKI was mentioned in a recent discharge letter. Both factors underline the relationship of patient information as being directly dependent on the physician's awareness, information and education [41].

\section{Physician's awareness of kidney disease during a hospital-stay for CHD}

Patients with kidney disease are also at a higher risk for complications in hospital stays for CHD and impaired prognosis after discharge [42, 43]. Causes for affected kidney function are multifactorial, including acutely reduced renal perfusion in myocardial infarction, nephrotoxic contrast application during catheter interventions, but also in elective CABG surgery [25]. These AKI episodes, which might be only temporary changes in kidney function of milder degree (e.g., a rise in $\mathrm{SCr}$ by $0.3 \mathrm{mg}$ / $\mathrm{dl}$ in AKI stage 1 [25]) are associated with an increased risk for cardiovascular events, cardiac dysfunction, heart failure progression, and risk of hospitalization and death [44].

In general, markers of kidney function at hospital admission and during the early phase of a hospital stay are more likely to be influenced by AKI, whereas kidney function might be improved and stabilized at hospital discharge. While in the core protocol of EUROASPIRE IV only SCr values at hospital admission were collected, at the German study center, we used all $\mathrm{SCr}$ 
measurements during the index hospital stay, thus enabling detailed analysis of the course of kidney function including AKI episodes. Of note, even if all methods were considered (e.g. urinary dip-stick, $24 \mathrm{~h}$ urine collection, ACR or total protein/creatinine ratio), in more than half of the patients no measure of proteinuria was available. Therefore, estimating the entire spectrum of kidney disease including proteinuria was impossible.

We found that during the index hospital stay, about $18 \%$ of patients experienced AKI, while most episodes were of stage 1 , but more severe stages including those needing hemodialysis were observed. Only a very small number of patients had a rise of SCr of exactly $0.3 \mathrm{mg} / \mathrm{dl}$ that did not further increase in subsequent laboratory measurements. Also about 18\% were found for impaired kidney function at hospital admission and at hospital discharge, respectively. Yet, one third of all patients was detected as having any impairment of kidney function either acute and/or chronic, respectively.

Since the introduction of equations based on $\mathrm{SCr}$ to estimating GFR, eGFR is increasingly displayed on routine laboratory reports with every $\mathrm{SCr}$ measurement [45], including the recruiting German EUROASPIRE IV centers. Therefore, information on kidney function is routinely visible to the treating physician. Moreover, the role of CKD and AKI as an important comorbid condition is widely discussed in the medical literature. The rationale for using mentioning of CKD or AKI in prominent parts of the hospital discharge letter as a proxy for physician's awareness of impaired kidney function was as follows: First, even slight changes in SCr need to be recognized by the physician as AKI, an important acute complication during the hospital stay. Second, either CKD or AKI reflect important risk factors for both CHD and CKD progression. Since the discharge letter represents the most important document of information transfer from the hospital to the ambulatory setting, the treating physician needs to judge kidney dysfunction as important enough to be clearly reported the discharge letter. In clinical routine in Germany, particularly the first part (diagnoses) and the end of the document (summary and medication) are predominantly being read by PCPs due to time constraints.

We found that the discharge letter reported only one fifth of patients with impaired kidney function (acute or chronic). While comorbid conditions, CHD history or the procedure itself were unrelated to physician's awareness, it was reassuring that higher stages of CKD or AKI increased chances for kidney dysfunction being reported in the discharge letter. Importantly, in patients in whom the index event was the primary diagnosis of CHD, impaired renal function was frequently not reported in the discharge letter. In particular in these patients, comprehensive description of traditional and non-traditional
$\mathrm{CV}$ risk factors is needed for establishing an individualized treatment concept for optimal secondary CHD prevention [46]. The discharge letter not only addresses the PCP, but also constitutes an important source for information to the patient himself, supporting self-empowerment, self-management and self-monitoring. Since reporting CKD or AKI in the discharge letter relates to patients' awareness of CKD, raising the physician's awareness of kidney disease may ultimately lead to better informed patients.

\section{Completeness of ICD-coding for kidney disease in patients with CHD}

In 2003/2004, the German Diagnosis Related Group (G-DRG) system replaced the cost-based reimbursement of hospital stays employing ICD diagnoses, procedures, and comorbidities [11]. For each case, coding usually gets completed a few days after discharge, commonly with the help of expert coding assistants. As AKI and $C K D$ increase the amount of reimbursement, adequate coding is highly relevant for the hospital. In our study, CKD and AKI were correctly coded for the majority of patients, in particular in those with advanced stages. However, there were still patients in whom adequate coding of renal function would have increased monetary benefits for the hospital.

\section{Strengths and limitations}

The unique setting of the EUROASPIRE IV study including the kidney module at the German study center allows a comprehensive view on CKD awareness among CHD patients and their treating physicians, however, limitations need to be mentioned. First, the studysample cannot be claimed as representative neither for CHD patients in Germany nor for those admitted for $\mathrm{CHD}$ at the recruiting hospitals due to the selection process of centers and the recruitment success [20]. Second, CKD at the EUROASPIRE IV study visit was classified based on a single measurement of $\mathrm{SCr}$ and ACR, while usually two independent measurements for adequate assessment of CKD are desired [24]. However, study participants were in apparently stable condition at the time of recruitment. In contrast, as also discussed above, during the index hospital stay, kidney function at admission as well as at discharge might be influenced by acute clinical circumstances, e.g. acute kidney injury at admission or the (prolonged) convalescence of kidney function after AKI. Third, any SCr-based estimation of GFR has limitations, and mild to moderately impaired kidney function may be better described by equations based on Cystatin C [47], which unfortunately was not available. However, we chose the SCr-based CKD-EPI formula as it outperforms the MDRD formula in particular in GFR between 60 and $90 \mathrm{ml} / \mathrm{min} / 1.73 \mathrm{~m}^{2}$ [48]. Fourth, the patient's knowledge of having been told 
about CKD may by influenced by multiple factors, including the setting of a study visit, therefore recall bias may apply. In addition, particularly in older subjects, a slight deterioration of kidney function might be considered as normal, age-related decline in GFR. Fifth, the number of variables tested in logistic regression analyses may be considered as too high, thus finding and missing associations by chance and limited power is surely possible. Finally, the substantial discrepancy between correct ICD-coding and presence of impaired kidney function in the discharge letter might be explained the fact that the discharge letter is predominantly prepared by junior physicians and may not reflect awareness by the more senior physician involved in care decisions, whereas the coding is supported by professional coders who may detect comorbid conditions that may have not been in the primary focus of the patient's therapeutic care.

\section{Conclusion}

In patients with CHD, mild to moderate CKD is a common comorbidity, but only few patients are aware of their renal dysfunction. Furthermore, in only a limited number of patients, renal impairment is being reported in hospital discharge letters, whereas the majority of subjects appears correctly ICD-coded. Stringent reporting of CKD and AKI may improve information transfer to care givers in the outpatient setting. How this may further lead to better informed patients, higher attainment of treatment targets, and improved management of both CKD and CHD should be focus of future studies.

\section{Abbreviations \\ ACR: Albumin / creatinine ratio; AKI: Acute kidney injury; AMI: Acute myocardial infarction; BMI: Body mass index; CABG: Coronary artery bypass grafting; CHD: Coronary heart disease; CHF: Congestive heart failure; Cl: Confidence interval; CKD: Chronic kidney disease; CKD-EPI: Chronic kidney disease epidemiology collaboration; CVD: Cardiovascular disease; eGFR: Estimated glomerular filtration rate; ESC: European Society of Cardiology; HDL-C: High density lipoprotein cholesterol; IQR: Inter-quartile range; KDIGO: Kidney disease - improving global outcomes; LDL-C: low density lipoprotein cholesterol; OR: Odds ratio; PCl: Percutaneous coronary intervention; SCr: Serum creatinine; SD: Standard deviation}

\section{Acknowledgements}

We thank the participants of the German EUROASPIRE IV survey for providing their data. We are thankful to all nurses, assistants, students, data managers and physicians at the recruiting centers for their time and effort on data collection. We gratefully acknowledge the support of A. Adamska (Dept. of Cardiovascular Medicine, National Heart and Lung Institute, Imperial College London, UK) for administrative assistance and M. Glemot and M. Konte (EURObservationalResearch Programme, European Heart House, Sophia-Antipolis, France) for data-management assistance within the EUROASPIRE IV survey. This publication was funded by the German Research Foundation (DFG) and the University of Wuerzburg in the funding programme Open Access Publishing.

\section{Funding}

The EUROASPIRE IV survey was carried out under the auspices of the European Society of Cardiology, EURObservational Research Programme and was supported by grants to the ESC from Amgen (EUROPE) GmbH, AstraZenecaAB, BMS/AstraZeneca, F. Hoffmann La Roche, GlaxoSmithKline $P L C$ and Merck\&Co. The researchers were independent of the funders who had no influence on study design, data collection, data analysis, data interpretation, decision to publish, or writing the manuscript. The German study center of the EUROASPIRE IV study was supported by the Comprehensive Heart Failure Center, sponsored by the German Federal Ministry of Education and Research (BMBF $01 E 01004$ and 01EO1504).

\section{Availability of data and materials}

The datasets generated during and/or analysed during the current study are property of the European Society of Cardiology and are not publicly available.

\section{Authors' contributions}

All authors contributed to the conception of the study and MW, CW, MS, StS, PUH contributed to study design. MW, MS, KK, DW, GF, MO, StS, PUH contributed to data acquisition and MW, MS, KH, VR contributed to data analysis, and MW, MS, CW, KK, MO, StS, PUH contributed to data interpretation. MW, MS, CW, StS and PUH drafted and all other authors critically revised the manuscript and all authors gave final gave final approval and agree to be accountable for all aspects of work ensuring integrity and accuracy.

\section{Ethics approval and consent to participate}

All patients provided written informed consent to take part in the study. The study was approved by the ethics committee of the Medical Faculty, University of Würzburg (Vote 58/12) and by the data protection officer of the University of Würzburg and the University Hospital Würzburg (DS-117.605-15/12). (see above, Methods section).

\section{Consent for publication}

Not applicable.

\section{Competing interests}

KK and DW had grant support from the European Society of Cardiology; KK received travel grants from Roche and Boehringer Ingelheim, DW reports honoraria for invited lectures or advisory boards: AstraZeneca, Merck Sharp and Dohme, Kowa Pharmaceuticals, Menarini, Zentiva; consultancy: Merck Sharp and Dohme. SS reports research grants from the German Ministry of Education and Research, European Union, University Hospital Würzburg; participation in Data Safety Monitoring and Event Adjudication Boards in trials sponsored by ROCHE and MEDTRONIC; principal investigator in trials (co-)sponsored by BOEHRINGER, NOVARTIS, BAYER, LUNDBECK; speaker honoraria by BOEHRINGER, SERVIER, NOVARTIS, ASTRA-ZENECA, PFIZER, BAYER. PUH reports research grants from the German Ministry of Research and Education, European Union, Charité, Berlin Chamber of Physicians, German Parkinson Society, University Hospital Würzburg, Robert-Koch-Institute, Charité-Universitätsmedizin Berlin (within MonDAFIS; MonDAFIS is supported by an unrestricted research grant to the Charité from Bayer), University Göttingen (within FIND-AF-randomized; FIND-AF randomized is supported by an unrestricted research grant to the University Göttingen from Boehringer-Ingelheim), and University Hospital Heidelberg (within RASUNOA-prime; RASUNOA-prime is supported by an unrestricted research grant to the University Hospital Heidelberg from Bayer, BMS, Boehringer-Ingelheim, Daiichi Sankyo), outside submitted work. All other authors have nothing to disclose relevant for the submitted work.

\section{Publisher's Note}

Springer Nature remains neutral with regard to jurisdictional claims in published maps and institutional affiliations.

\section{Author details}

${ }^{1}$ Institute of Clinical Epidemiology and Biometry, University of Würzburg, Petrinistr. 33a, 97080 Würzburg, Germany. ${ }^{2}$ Division of Nephrology, Department of Medicine I, University Hospital Würzburg, Würzburg, Germany. ${ }^{3}$ Comprehensive Heart Failure Center, University of Würzburg, Würzburg, Germany. ${ }^{4}$ Department of Cardiovascular Medicine, National Heart and Lung Institute, Imperial College London, London, UK. ${ }^{5}$ Department of Public Health, University of Ghent, Ghent, Belgium. Institute of Informatics VI, University of Würzburg, Würzburg, Germany. ${ }^{7}$ Department of Cardiovascular Surgery, University Hospital Würzburg, Würzburg, Germany. ${ }^{8}$ Division of Cardiology, Department of Medicine I, University Hospital Würzburg, Würzburg, Germany. ${ }^{9}$ Clinical Trial Center, University Hospital Würzburg, Würzburg, Germany. ${ }^{10}$ Fellow of the European Society of Cardiology, Sophia Antipolis, France. 
Received: 23 February 2017 Accepted: 29 September 2017 Published online: 25 October 2017

\section{References}

1. Anavekar NS, McMurray JJ, Velazquez EJ, et al. Relation between renal dysfunction and cardiovascular outcomes after myocardial infarction. N Engl J Med. 2004;351(13):1285-95.

2. Azar RR, Prpic R, Ho KK, et al. Impact of end-stage renal disease on clinical and angiographic outcomes after coronary stenting. Am J Cardiol. 2000; 86(5):485-9

3. Bruck K, Stel VS, Gambaro G, et al. CKD prevalence varies across the european general population. J Am Soc Nephrol. 2016;27(7):2135-47.

4. Gansevoort RT, Correa-Rotter R, Hemmelgarn BR, et al. Chronic kidney disease and cardiovascular risk: epidemiology, mechanisms, and prevention. Lancet. 2013;382(9889):339-52.

5. Go AS, Chertow GM, Fan D, et al. Chronic kidney disease and the risks of death, cardiovascular events, and hospitalization. N Engl J Med. 2004; 351(13):1296-305

6. Ix JH, Mercado N, Shlipak MG, et al. Association of chronic kidney disease with clinical outcomes after coronary revascularization: the arterial revascularization therapies study (ARTS). Am Heart J. 2005;149(3):512-9.

7. Coresh J, Selvin E, Stevens LA, et al. Prevalence of chronic kidney disease in the United States. JAMA. 2007;298(17):2038-47.

8. Di Angelantonio E, Chowdhury R, Sarwar N, et al. Chronic kidney disease and risk of major cardiovascular disease and non-vascular mortality: prospective population based cohort study. BMJ. 2010;c4986:341.

9. Tonelli $M$, Jose $P$, Curhan $G$, et al. Proteinuria, impaired kidney function, and adverse outcomes in people with coronary disease: analysis of a previously conducted randomised trial. BMJ. 2006;332(7555):1426.

10. van Domburg RT, Hoeks SE, Welten GM, et al. Renal insufficiency and mortality in patients with known or suspected coronary artery disease. J Am Soc Nephrol. 2008;19(1):158-63.

11. INEK - Institut für das Entgeltsystem im Krankenhaus. DRG-Fallpauschalen Kalkulationshandbuch. 2016. http://www.g-drg.de/cms/Kalkulation2/DRG Fallpauschalen_17b_KHG. Accessed 11 Aug 2016.

12. Black C, Sharma P, Scotland G, et al. Early referral strategies for management of people with markers of renal disease: a systematic review of the evidence of clinical effectiveness, cost-effectiveness and economic analysis. Health Technol Assess. 2010;14(21):1-184.

13. Tangri N, Stevens LA, Griffith J, et al. A predictive model for progression of chronic kidney disease to kidney failure. JAMA. 2011;305(15):1553-9.

14. Boulware LE, Carson KA, Troll MU, et al. Perceived susceptibility to chronic kidney disease among high-risk patients seen in primary care practices. J Gen Intern Med. 2009;24(10):1123-9.

15. Plantinga LC, Boulware LE, Coresh J, et al. Patient awareness of chronic kidney disease: trends and predictors. Arch Intern Med. 2008;168(20):2268-75.

16. Alm-Roijer C, Stagmo M, Uden G, et al. Better knowledge improves adherence to lifestyle changes and medication in patients with coronary heart disease. Eur J Cardiovasc Nurs. 2004;3(4):321-30.

17. Whaley-Connell A, Sowers JR, McCullough PA, et al. Diabetes mellitus and CKD awareness: the kidney early evaluation program (KEEP) and National Health and nutrition examination survey (NHANES). Am J Kidney Dis. 2009; 53(4 Suppl 4):S11-21.

18. Kotseva K, De Bacquer D, Jennings $C$, et al. Adverse lifestyle trends counter improvements in cardiovascular risk factor management in coronary patients. J Am Coll Cardiol. 2015;66(14):1634-6

19. Kotseva K, Wood D, De Backer G, et al. Cardiovascular prevention guidelines in daily practice: a comparison of EUROASPIRE I, II, and III surveys in eight European countries. Lancet. 2009:373(9667):929-40.

20. Kotseva K, Wood D, De Bacquer D, et al. EUROASPIRE IV: a European Society of Cardiology survey on the lifestyle, risk factor and therapeutic management of coronary patients from 24 European countries. Eur J Prev Cardiol. 2016;23(6):636-48.

21. McClellan WM, Newsome BB, McClure LA, et al. Chronic kidney disease is often unrecognized among patients with coronary heart disease: the REGARDS cohort study. Am J Nephrol. 2009:29(1):10-7.

22. Middleton ET, Morice AH. Breath carbon monoxide as an indication of smoking habit. Chest. 2000;117(3):758-63.

23. Kaspar M, Ertl M, Fette $G$, et al. Data linkage from clinical to study databases via an $\mathrm{R}$ data warehouse user interface. Experiences from a large clinical follow-up study. Methods Inf Med. 2016;55(4):381-6.
24. Kidney Disease Improving Global Outcomes (KDIGO) CKD Work Group. KDIGO Clinical Practice Guideline for the Evaluation and Management of Chronic Kidney Disease. Kidney Inter. 2013;(Suppl 3):1-150.

25. Kidney Disease Improving Global Outcomes (KDIGO) AKI Work Group. KDIGO clinical practice guideline for acute kidney injury. Kidney Inter. 2012; (Suppl 2):1-138.

26. Kintscher U, Böhm M, Goss F, et al. Kommentar zur 2013-ESH/ESC-Leitlinie zum management der arteriellen Hypertonie. Kardiologe. 2014;8(3):223-30.

27. Hsu CC, Hwang SJ, Wen CP, et al. High prevalence and low awareness of CKD in Taiwan: a study on the relationship between serum creatinine and awareness from a nationally representative survey. Am J Kidney Dis. 2006; 48(5):727-38.

28. Tuot DS, Plantinga LC, Judd SE, et al. Healthy behaviors, risk factor control and awareness of chronic kidney disease. Am J Nephrol. 2013;37(2):135-43.

29. Mclntyre NJ, Fluck R, Mclntyre C, et al. Treatment needs and diagnosis awareness in primary care patients with chronic kidney disease. Brit J Gen Pract. 2012;62(597):e227-32.

30. Wright Nunes JA, Wallston KA, Eden SK, et al. Associations among perceived and objective disease knowledge and satisfaction with physician communication in patients with chronic kidney disease. Kidney Int. 2011; 80(12):1344-51.

31. Plantinga LC, Tuot DS, Powe NR. Awareness of chronic kidney disease among patients and providers. Adv Chronic Kidney Dis. 2010;17(3):225-36.

32. Cavanaugh KL, Merkin SS, Plantinga LC, et al. Accuracy of patients' reports of comorbid disease and their association with mortality in ESRD. Am J Kidney Dis. 2008:52(1):118-27.

33. Jafar TH, Allen JC, Jehan I, et al. Health education and general practitioner training in hypertension management: long-term effects on kidney function. Clin J Am Soc Nephrol. 2016;11(6):1044-53.

34. Hare DL, Toukhsati SR, Johansson P, et al. Depression and cardiovascular disease: a clinical review. Eur Heart J. 2014:35(21):1365-72.

35. Tsai YC, Chiu YW, Hung CC, et al. Association of symptoms of depression with progression of CKD. Am J Kidney Dis. 2012;60(1):54-61.

36. Jones C, Roderick P, Harris S, et al. Decline in kidney function before and after nephrology referral and the effect on survival in moderate to advanced chronic kidney disease. Nephrol Dial Transplant. 2006;21(8):2133-43.

37. Jungers $P$, Massy ZA, Nguyen-Khoa T, et al. Longer duration of predialysis nephrological care is associated with improved long-term survival of dialysis patients. Nephrol Dial Transplant. 2001:16(12):2357-64.

38. Girndt M, Trocchi P, Scheidt-Nave C, et al. The prevalence of renal failure. Results from the German health interview and examination survey for adults, 2008-2011 (DEGS1). Dtsch Arztebl Int. 2016;113(6):85-91.

39. Chronic Kidney Disease Prognosis Consortium, Matsushita K, van der Velde $M$, et al. Association of estimated glomerular filtration rate and albuminuria with all-cause and cardiovascular mortality in general population cohorts: a collaborative meta-analysis. Lancet. 2010;375(9731):2073-81.

40. Ronco C, Haapio M, House AA, et al. Cardiorenal syndrome. J Am Coll Cardiol. 2008:52(19):1527-39.

41. Kaplan SH, Greenfield S, Ware JE Jr. Assessing the effects of physicianpatient interactions on the outcomes of chronic disease. Med Care. 1989; 27(3 Suppl):S110-27.

42. Bohlouli B, Tonelli M, Jackson T, et al. Risk of hospital-acquired complications in patients with chronic kidney disease. Clin J Am Soc Nephrol. 2016;11(6):956-63.

43. Pinkau T, Mann JF, Ndrepepa G, et al. Coronary revascularization in patients with renal insufficiency: restenosis rate and cardiovascular outcomes. Am J Kidney Dis. 2004:44(4):627-35.

44. Odutayo A, Wong CX, Farkouh $M$, et al. AKI and long-term risk for cardiovascular events and mortality. J Am Soc Nephrol. 2017:28(1):377-87.

45. Accetta NA, Gladstone EH, DiSogra C, et al. Prevalence of estimated GFR reporting among US clinical laboratories. Am J Kidney Dis. 2008:52(4):778-87.

46. Task Force Members, Montalescot G, Sechtem U, et al. 2013 ESC guidelines on the management of stable coronary artery disease: the task force on the management of stable coronary artery disease of the European Society of Cardiology. Eur Heart J. 2013;34(38):2949-3003.

47. Inker $\mathrm{LA}$, Schmid $\mathrm{CH}$, Tighiouart $\mathrm{H}$, et al. Estimating glomerular filtration rate from serum creatinine and cystatin C. N Engl J Med. 2012;367(1):20-9.

48. Levey AS, Stevens LA. Estimating GFR using the CKD epidemiology collaboration (CKD-EPI) creatinine equation: more accurate GFR estimates, lower CKD prevalence estimates, and better risk predictions. Am J Kidney Dis. 2010;55(4):622-7. 